\title{
Research on Green Compound Corrosion Inhibitors of Carbon Steel
}

\section{in Natural Seawater}

\author{
Fu Qiang ${ }^{1, a}$ and Xiaogang Yang ${ }^{2, b}$ \\ 1.Electric Power Research Institute of Guangdong Power Grid Corporation, Guangzhou 510080, \\ China \\ 2.College of Environment and Safety Engineering, Qingdao University of Science \\ and Technology, Qingdao, 266042, China \\ afuqiang7293@163.com, byxg95@126.com
}

\begin{abstract}
Keywords: corrosion inhibitor, carbon steel, natural seawater, weight loss, polarization curve Abstract: A kind of green compound corrosion inhibitor has been made from sodium molybdate, benzotriazole, calcium gluconate, sodium polyphosphate and zinc sulfate. The inhibition capability of the corrosion inhibitor in seawater for carbon steel is carried out by weight-loss method and electrochemical method. The effect of different inhibitors concentration on the corrosion efficiency is also studied. The results show that the presence of these compounds in seawater suppresses anodic processes and when the dosage of sodium molybdate is $60 \mathrm{mg} / \mathrm{L}$, benzotriazole $60 \mathrm{mg} / \mathrm{L}$, calcium gluconate is $120 \mathrm{mg} / \mathrm{L}$, sodium polyphosphate is $60 \mathrm{mg} / \mathrm{L}$ and zinc sulfate is $120 \mathrm{mg} / \mathrm{L}$, the corrosion inhibition effects of carbon steel are pretty good. Carbon steel corrosion inhibition efficiency reaches $95.53 \%$ in seawater for 15 days.
\end{abstract}

\section{Introduction}

With the shortage of fresh water resources, it is concerned about to utilize seawater instead of fresh water as supplement water of recirculating cooling water system. ${ }^{[1]}$ This technology has important technical and economic value ${ }^{[2]}$ But seawater is electrolyte solution with multiple salts, mainly $3.0 \% \sim 5.0 \%$ sodium chloride, $\mathrm{pH}$ value about 8 , and dissolving a certain oxygen ${ }^{[3]}$ Natural seawater easily leads to pipeline and heat exchanger in the recirculating cooling water system corrosion. So it is imminent to solve piping and equipment corrosion problem in the seawater utilization. Carbon steel is used in the recirculating cooling water system generally owing to its excellent mechanical properties and low cost. Corrosion and corrosion inhibition of carbon steel have gotten great attention in recirculating cooling water system. ${ }^{[4,5]}$ The common methods to control and prevent equipment corrosion have using resistant material, using cooling water anticorrosion coating, increasing $\mathrm{pH}$ value of the cooling water system and adding corrosion inhibitor. ${ }^{[6-9]}$ Among these methods using resistant material can protect equipment effectively, but the prime cost is too high. The technology of anticorrosion coating is complex and it is fit for local anticorrosion in the system. Increasing cooling water $\mathrm{pH}$ value makes mild steel deactivation easily. Adding corrosion inhibitor can protect the whole system and it is economical and practical. At present it is widely used.

The development of seawater corrosion inhibitor undergoes from inorganic to organic, from single to compound, from single inhibition type to mixed inhibition type. Many organic molecules exhibit high anti- corrosion potential, but they pollute the environment during their synthesis and applications. ${ }^{[10,11]}$ The effect of single seawater corrosion inhibitor is unsatisfactory in general, so two types or several types compound coordinate use to improve inhibition efficiency. ${ }^{[12]}$

The aim of the present work is to study the effect of compound corrosion inhibitors for carbon steel in natural seawater for 15 days using weight loss and electrochemical polarization curve measurements. The effect of inhibitors concentrations on the inhibition efficiency of carbon steel in free and inhibited natural seawater was also investigated. 


\section{Experimental Procedure}

\section{Materials}

The steel used in this study is a carbon steel with a chemical composition (in wt \%) of $0.14-0.22 \%$ $\mathrm{C}, 0.3-0.65 \% \mathrm{Mn}, \leqslant 0.3 \% \mathrm{Si}$. The size of sample is about $5 \mathrm{~cm} \times 2.5 \mathrm{~cm} \times 0.3 \mathrm{~cm}$ (length $\times$ wide $\times$ thick). The carbon steel samples were pre-treated prior to the experiments by polishing with silicon carbide paper $(240,600$, and 800), then rinsed with absolute ethyl alcohol, degreased in acetone for 5 minute, blown dry with cold air blast, and then dried in desiccator at room temperature for 6 hours. After dried, the samples were weighed and measured length, wide and thick to calculate sample area. The corrosion inhibitors were sodium molybdate, benzotriazole, calcium gluconate, sodium polyphosphate and zinc sulfate.The seawater chose from Qingdao First Bathing Beach waters.

\section{Measurements}

\section{Weight loss measurements}

The experiment was carried out in a beaker containing 1L natural seawater. Three clean preweighed carbon steels as duplicate samples were immersed completely in $1 \mathrm{~L}$ natural seawater with and without the addition of different concentrations of corrosion inhibitors at room temperature. After 15 days immersion in natural seawater, the specimens were withdraw, rinsed with pickling solution, washed with acetone, dried, and weighed. The inhibition efficiency (IE\%) was calculated as Eq.1:

$\operatorname{IE}(\%)=\left[\left(\mathrm{V}_{0}-\mathrm{V}\right) / \mathrm{V}_{0}\right] \times 100$

where $\mathrm{V}_{0}$ and $\mathrm{V}$ are the corrosion rate of the mild carbon steel in the absence and presence of inhibitor, respectively.

Corrosion rate $(\mathrm{V})$ was calculated as Eq.2:

$\mathrm{V}=\left(\mathrm{W}_{0}-\mathrm{W}_{1}-\mathrm{W}_{2}\right) / \mathrm{A} \cdot \mathrm{t}$

where $\mathrm{W}_{0}, \mathrm{~W}_{1}$ and $\mathrm{W}_{2}$ are the sample original weight, the same sample weight after removal of corrosion products and the blank sample correction weight loss (weightlessness in air) respectively. A is the sample area. $t$ is experimental period.

\section{Electrochemical polarization curve measurements}

Electrochemical studies were carried out using CS multi-channel electrochemical workstation. A three-electrode cell system was employed for the measurement; mild steel with an exposed area of 1 $\mathrm{cm}^{2}$ acts as a working electrode, whereas platinum wire and saturated calomel electrode acts as a counterelectrode and reference electrode, respectively. The measurements were performed in seawater without and with different inhibitor concentrations in an aerated environment. All polarization curves were recorded at room temperature, and the electrodes were immersed in the test solution for 30 minutes at natural potential to attain steady state before measurement.

\section{Results and discussion}

\section{Effect of sodium molybdate concentration on inhibition efficiency and polarization curves}

From the inhibition efficiencies obtained from the weight loss experiments for mild steel in natural seawater, it is found that the inhibition efficiency is highest with sodium molybdate concentration $60 \mathrm{mg} / \mathrm{L}$, which is evident from Fig. 1 (a). Sodium molybdate belongs to anode type inhibitor and 
polarization curve obtained with inhibitor occurs positive shift compared with blank polarization curve, which can be obtained from Fig. 1 (b). Protective film formed with molybdate is dense relatively and can prevent chloride ion corrosion. Molybdate also can compound other inhibitors to form oxide film, deposited film and adsorption film on carbon steels surface to inhibit its corrosion.

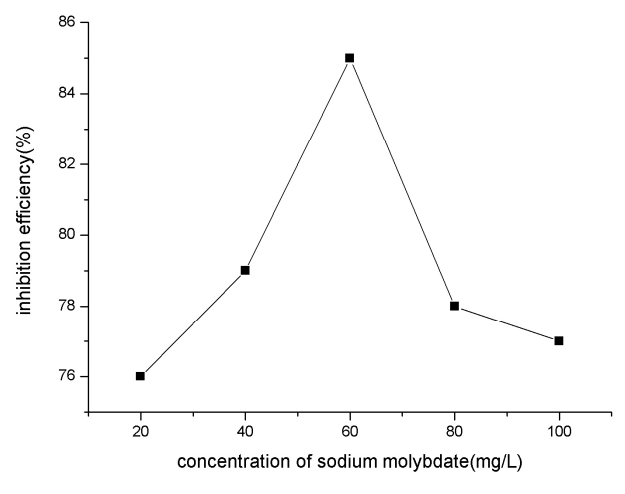

(a)

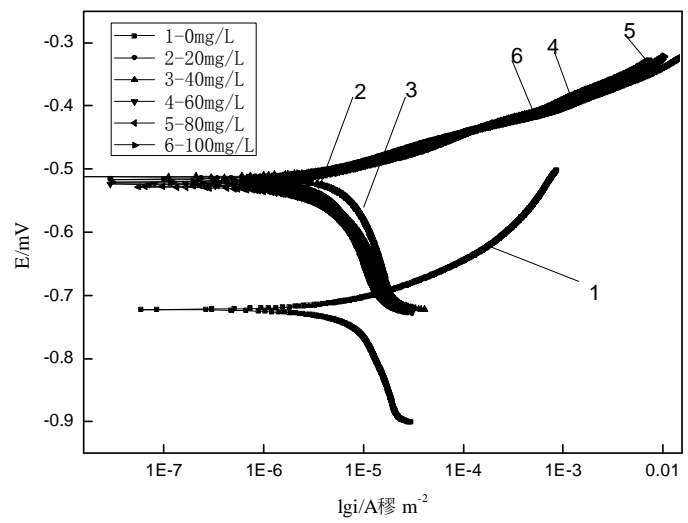

(b)

Fig. 1 Effect of sodium molybdate concentration on inhibition efficiency (a) and polarization curves

(b) on mild steel in natural seawater of 15 days

\section{Effect of calcium gluconate concentration on inhibition efficiency and polarization curves}

From Fig. 2(a) it is shown that inhibition efficiency increases maximum and then decrease with increasing concentration of the calcium gluconate, when calcium gluconate concentration is $120 \mathrm{mg} / \mathrm{L}$, the inhibition efficiency is highest. Fig. 2(b) shows that calcium gluconate is also anode type inhibitor. Glucose ion can easily chelate other ions to form protection film on the carbon steel surface and restrain chloride ion corrosion.

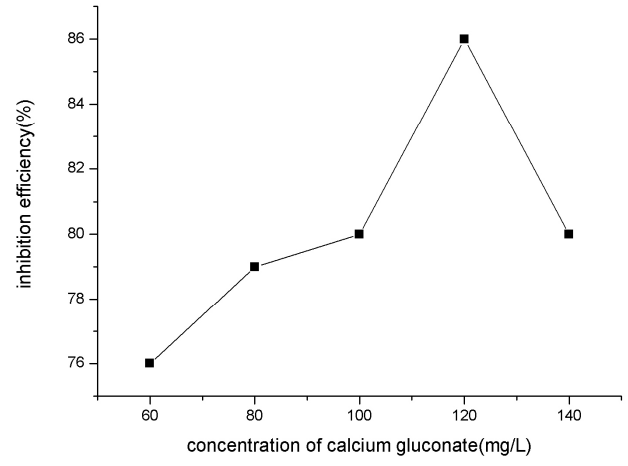

(a)

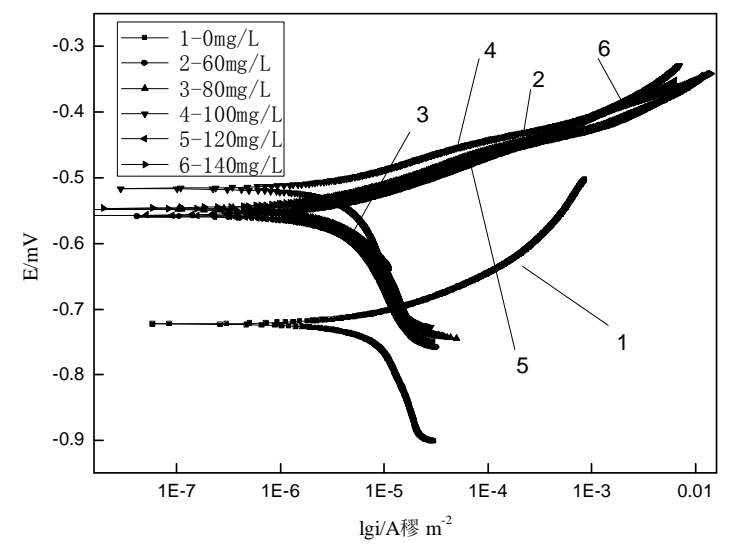

(b)

Fig. 2 Effect of calcium gluconate concentration on inhibition efficiency (a) and polarization curves

(b) on mild steel in natural seawater of 15 days

\section{Effect of zinc sulfate concentration on inhibition efficiency and polarization curves}

Also through the weight loss experiments, it is found that the inhibition efficiency basically increases with zinc sulfate concentration increasing, but after zinc sulfate concentration is more than $120 \mathrm{mg} / \mathrm{L}$, the inhibition efficiency changes little which is obvious from Fig. 3(a). The optimum concentration of zinc sulfate chooses $120 \mathrm{mg} / \mathrm{L}$. Fig. 3(b) shows that inhibition mechanism is anode type inhibition. Zinc ion of zinc sulfate can form zinc hydroxide rapidly in water depositing anode surface to play a protective role. Zinc sulfate forms film quickly, but the film does not firm, so it is often used compounding with other inhibitors. 


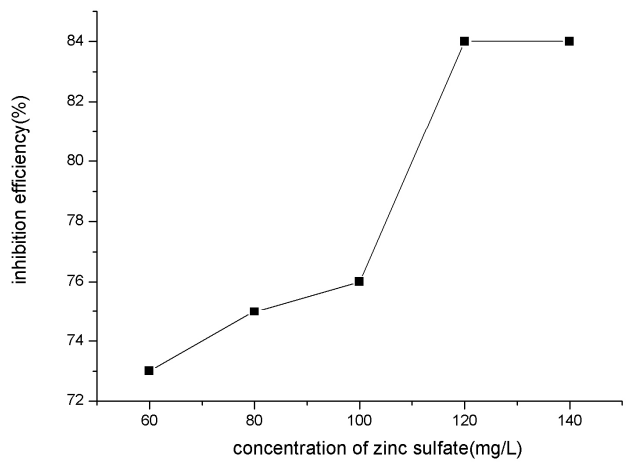

(a)

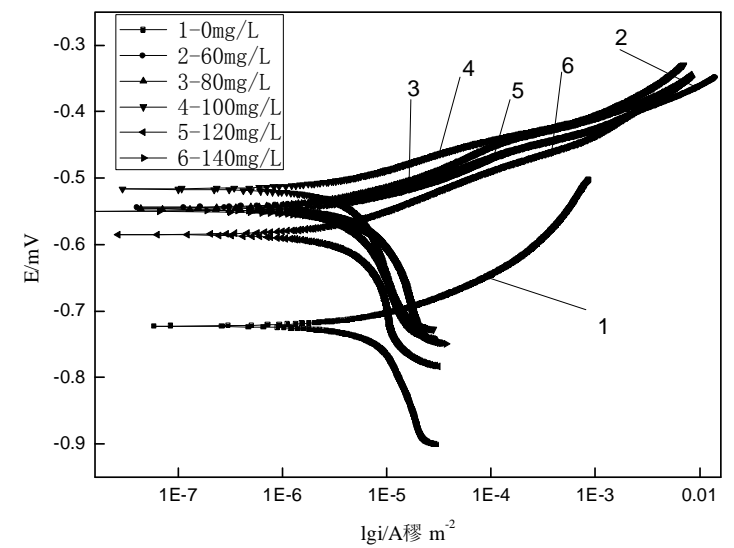

(b)

Fig. 3 Effect of zinc sulfate concentration on inhibition efficiency (a) and polarization curves

(b) on mild steel in natural seawater of 15 days

\section{Effect of sodium polyphosphate concentration on inhibition efficiency and polarization curves}

It can be seen from Fig. 4(a) that sodium polyphosphate concentration has obvious effect on inhibition efficiency. When the concentration is $60 \mathrm{mg} / \mathrm{L}$, the inhibition efficiency is the highest. The inhibition efficiency increases maximum and then decrease with increasing concentration of the sodium polyphosphate. Sodium polyphosphate can coordinate with divalent iron ions and tervalence iron ions to form sodium ferric polyphosphate coordination ion and form compact precipitation film by current electrodeposition on anode surface. Overall considerration the concentration of sodium polyphosphate chooses $60 \mathrm{mg} / \mathrm{L}$. Fig. 4(b) indicates that sodium polyphosphate is typical anode precipitation type inhibitor.

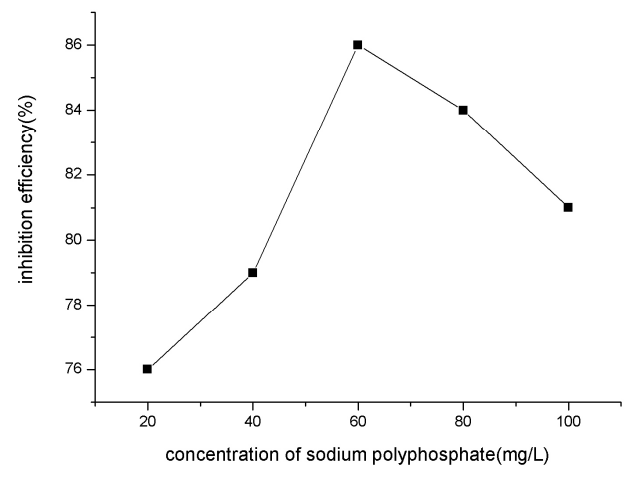

(a)

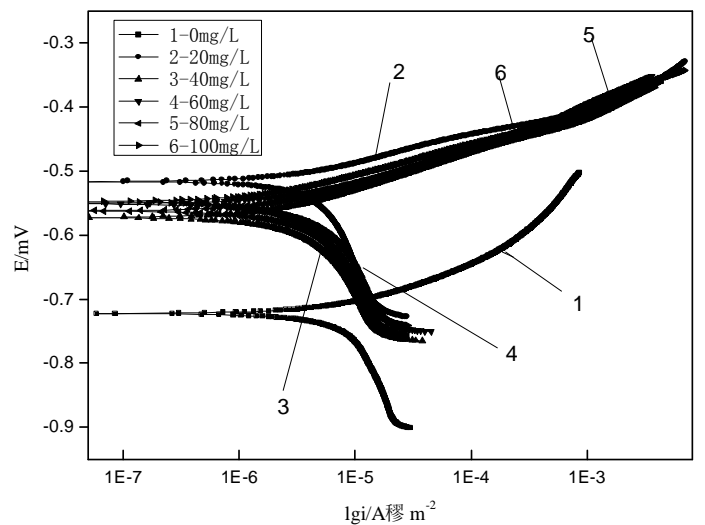

(b)

Fig. 4 Effect of sodium polyphosphate concentration on inhibition efficiency (a) and polarization curves

(b) on mild steel in natural seawater of 15 days

\section{Effect of benzotriazole concentration on inhibition efficiency and polarization curves}

Benzotriazole can be used as adsorption type inhibitor and its protection role lies in forming protection film on steel surface. After the film forms, metal isolates from corrosion medium and the corrosion stops. Fig. 5 (a) shows when benzotriazole concentration is $60 \mathrm{mg} / \mathrm{L}$, the inhibition efficiency is the highest. Fig. 5 (b) also proves benzotriazole is a kind of anode type inhibitor. 


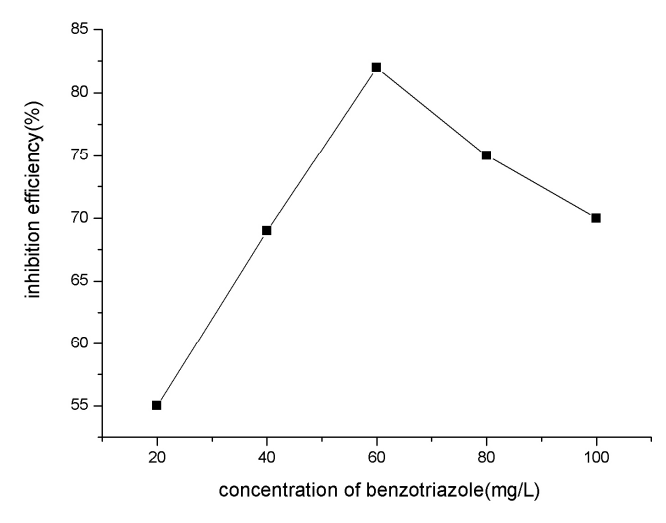

(a)

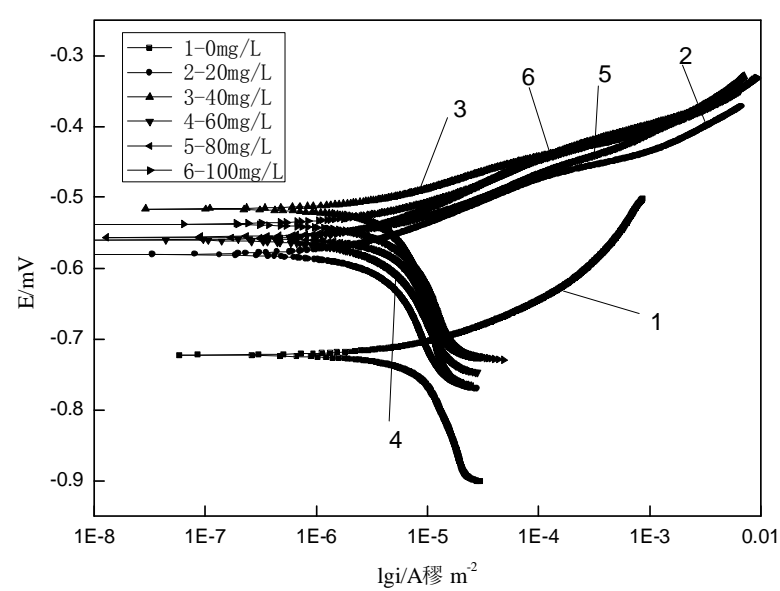

(b)

Fig. 5 Effect of benzotriazole concentration on inhibition efficiency (a) and polarization curves

(b) on mild steel in natural seawater of 15 days

By weight-loss measurement, the optimal inhibition efficiency reaches $95.53 \%$ with compound inhibitor components and concentrations as sodium molybdate $60 \mathrm{mg} / \mathrm{L}$, benzotriazole $60 \mathrm{mg} / \mathrm{L}$, calcium gluconate $120 \mathrm{mg} / \mathrm{L}$, sodium polyphosphate $60 \mathrm{mg} / \mathrm{L}$ and zinc sulfate $120 \mathrm{mg} / \mathrm{L}$ at room temperature for 15 days.

\section{Conclusions}

The corrosion behavior of carbon steel is investigated in natural seawater with and without addition of various concentrations of compound inhibitors, using weight-loss and electrochemical techniques. Sodium molybdate, benzotriazole, calcium gluconate, sodium polyphosphate and zinc sulfate are found to be good adsorption inhibitor for the corrosion of carbon steel in natural seawater. The polarization curves indicate that sodium molybdate, benzotriazole, calcium gluconate, sodium polyphosphate and zinc sulfate affect anodic Tafel slopes, and are thus a mixed type inhibitor. The inhibition is due to the adsorption of the inhibitor molecules on the carbon steel surface and blocking of active sites. The inhibitor concentration has important effect on the inhibition efficiency. When the dosage of sodium molybdate is $60 \mathrm{mg} / \mathrm{L}$, benzotriazole is $60 \mathrm{mg} / \mathrm{L}$, calcium gluconate is $120 \mathrm{mg} / \mathrm{L}$, sodium polyphosphate is $60 \mathrm{mg} / \mathrm{L}$ and zinc sulfate is $120 \mathrm{mg} / \mathrm{L}$, the corrosion inhibition effects of carbon steel are pretty good. Carbon steel corrosion inhibition efficiency reaches $92.53 \%$ in seawater for 15 days.

\section{References}

[1] M.G. Fontana. Corrosion Engineering, 3rd ed., McGraw-Hill, NewYork, 1986, 86.

[2] A. El Warraky, H.A. El Shayeb, E.M. Sherif. Anti-Corros. Methods Mater., 2004, 51,52-61.

[3] Uhlig, H.H., Revic, R.W..Corrosion and Corrosion Control.Wiley, New York ,1985.

[4] G. Meng, L. Wei, T. Zhang, Y. Shao, F. Wang. Corrosion Science, 2009,51,2151.

[5] F.H. Latief, E.-S.M. Sherif. J. Ind. and Eng. Chem, 2012,18,2129.

[6] Ravichandra,n R., Nanjundan, S., Rajendran, N.,J. Appl. Electrochem., 2004, 34, 1171.

[7] L. Zhong, M.S. Goldberg, Y.T. Gao, J.A. Hanley. Epidemiology, 2001, 12, 695-700.

[8] M.H. Hussin , M.J. Kassim. Mater. Chem. Phys., 2011, 125, 461-468.

[9] R.P. Bothi, R.A. Abdul, O. Hasnah, A. Khalijah: Acta Phys.Chim. Sin., 2010, 26, 2171.

[10] Arab S.T., Al-Turkustani A.M., Al-Nami S. Y.. Mater. Sci. Res. Ind. 2005,3,99.

[11] P. Kern, D. Landolt, Y. Abboud. J. Electrochem. Soc., 2001, 237, 228.

[12] M.N. Katariya, A.K. Jana, P.A. Parikh. J. Ind. and Eng. Chem., 2013,19,286. 